\title{
Chemotherapy for the treatment of malignant peripheral nerve sheath tumors in neurofibromatosis 1: a 10-year institutional review
}

Ouidad Zehou ${ }^{1 \dagger}$, Elizabeth Fabre ${ }^{2 \dagger}$, Laurent Zelek ${ }^{3}$, Emilie Sbidian$^{1}$, Nicolas Ortonne ${ }^{4}$, Eugeniu Banu ${ }^{5}$, Pierre Wolkenstein ${ }^{1 \dagger}$ and Laurence Valeyrie-Allanore ${ }^{1,6^{*}+}$

\begin{abstract}
Background: Neurofibromatosis 1 (NF1) is the most common autosomal dominant disorder, with an incidence of 1 in 2,500-3,300 live births. NF1 is associated with significant morbidity and mortality because of complications, especially malignant peripheral nerve sheath tumors (MPNSTs), which mainly develop during adulthood. We evaluated our experience with management of NF1 with MPNSTs by standard chemotherapy with anthracycline and/or ifosfamide in terms of time to treatment failure and overall survival.

Methods: We performed a retrospective review of consecutive patients with NF1 and a diagnosis of MPNSTs between 1993 and 2003 in our referral center for NF1. Prognostic factors were evaluated by univariate analysis.

Results: We evaluated data for 21 patients with grade $1(n=1)$, grade $2(n=8)$ and grade $3(n=12)$ MPNST; 16 presented localized disease and underwent surgery: margins for 6 were tumor-free (including 3 patients with amputation), 2 showed microscopic residual disease and 8 showed macroscopic residual disease. All patients received chemotherapy and 9 radiotherapy. Median time to treatment failure and overall survival were 7.8 and 17 months, respectively. Two patients were still alive at 138 and 167 months. We found no significant relationship between type of chemotherapy and time to treatment failure or overall survival.

Conclusions: MPNSTs are highly aggressive in NF1. Conventional chemotherapy does not seem to reduce mortality, and its role must be questioned. Recent advances in the molecular biology of MPNSTs may provide new prognostic factors and targeted therapies.
\end{abstract}

Keywords: Neurofibromatosis 1, Malignant peripheral nerve sheath tumor, Soft tissue sarcoma, Chemotherapy

\section{Background}

Malignant peripheral nerve sheath tumors (MPNSTs) are uncommon, representing about $5 \%$ of soft-tissue sarcomas. Neurofibromatosis 1 (NF1) is one of the most common autosomal dominant disorders, with an incidence of 1 in 2,500-3,300 live births. It is associated with mutation in Nf1, a tumor suppressor located on chromosome 17q11.2. Nf1 encodes neurofibromin, a protein of the ras signal transduction pathway [1]. NF1 is

\footnotetext{
* Correspondence: laurence.allanore@hmn.aphp.fr

${ }^{\dagger}$ Equal contributors

'Department of Dermatology, Referral center for Neurofibromatosis, Henri Mondor Hospital, UPEC, Créteil, France

${ }^{6}$ Department of Dermatology, Henri-Mondor Hospital, 51 Av du Maréchal de Lattre de Tassigny, F-94010 Créteil Cedex, France

Full list of author information is available at the end of the article
}

characterized by neurofibromas, café au lait spots, intertriginous freckling, bone malformations, learning disabilities and iris hamartomas [1].

NF1 has a significant morbidity and mortality because of various complications, especially benign and/or malignant tumors. Neurofibromas are benign tumors mostly composed of Schwann cells, perineurium like-cells, fibroblasts and mast cells. Cutaneous neurofibromas greatly affect quality of life; subcutaneous, nodular and internal neurofibromas act mainly through compression and can transform into MPNSTs. Several clinical features such as internal or subcutaneous neurofibromas are predictors of mortality with NF1 [1,2]. Patients with subcutaneous neurofibromas are 3 times more likely to have internal plexiform neurofibromas and MPNSTs. In

\section{Biomed Central}

(c) 2013 Zehou et al.; licensee BioMed Central Ltd. This is an Open Access article distributed under the terms of the Creative Commons Attribution License (http://creativecommons.org/licenses/by/2.0), which permits unrestricted use, distribution, and reproduction in any medium, provided the original work is properly cited. 
those with internal plexiform neurofibromas, MPNSTs are 20 times more likely to develop [1]. The overall risk of cancer is more than three-fold greater than in the general population, and MPNSTs are the leading cause of death during adulthood [3,4]. Hence, the lifetime risk of MPNSTs is about $8 \%$ to $13 \%$ [5-8].

An enlarged mass, neurological deficits and pain can predict malignant transformation of MPNSTs [9]. These NF1 MPNSTs are associated with poor prognosis; the 5year survival rate is between $16 \%$ and $38 \%$ [7,10-15]. Limited disease is treated by wide excision along with radiation therapy for high-risk tumors defined as intermediate- to high-grade deep tumors with a diameter $>5 \mathrm{~cm}$ [16]. Adjuvant chemotherapy is not standard treatment in adult-type soft-tissue sarcomas and can be proposed for high-risk tumors. Extensive disease is treated with anthracycline-based chemotherapy. Ifosfamide may be discussed for patients with good performance status [16].

Here we retrospectively examined our experience with the management of MPNSTs by standard chemotherapy with anthracycline and/or ifosfamide in patients with NF1 and evaluated prognostic factors of time to treatment failure and overall survival.

\section{Methods}

\section{Patients}

We included data for all consecutive NF1 patients with a diagnosis of MPNST between February 1993 and November 2003 who underwent chemotherapy in our institution, a French national referral center for neurofibromatoses. Data on clinico-pathological features and other variables were collected from medical charts and included medical history; demographic characteristics (gender, age); clinical presentation, including pain, motor or sensitive deficits, tumor location and size (the largest diameter assessed by CT or MRI before surgery and/or chemotherapy); intraoperative and macroscopic pathological evaluation; metastatic status; histopathological grade of the primary tumor according to the Federation Nationale des Centres de Lutte Contre le Cancer (FNCLCC) classification [17]; clinical evolution; and treatment-related variables (type of surgery, chemotherapy and radiotherapy). Initial staging was based on chest and abdomen CT scans.

A multidisciplinary medical team validated all treatments according to local and national guidelines. Surgery was performed to achieve local control with tumorfree margins. Extent of tumor resection was evaluated from the surgeon's notes, charts and pathological reports. Surgical resection was considered macroscopically complete (no visible tumor remaining) or incomplete ( $\mathrm{R} 2=$ gross tumor remaining post-operatively). Microscopically, tumor margins were defined as involved
(R1=residual disease) or tumor-free (R0). Postoperative radiotherapy involved irradiation of all dissected tissues with a large field. Radiation therapy was administered at a dose of 50-66 Gy, from 1.8 to 2 Gy. Chemotherapy involved 6 cycles of doxorubicin, $60 \mathrm{mg} / \mathrm{m}^{2}$, delivered every 21 days. Ifosfamide, $2500 \mathrm{mg} / \mathrm{m}^{2}$, was given at days 1-3 for patients with performance status $0-1$. Patients received doxorubicin and/or ifosfamide or another regimen, depending on their performans status and past medical history.

All patients were followed until death or the last known visit. Patients who underwent surgery were seen 1 month after hospital discharge. Every 3 months thereafter, physical and radiological examinations were performed. Recurrence was defined as tumor growth occurring at the excision site at least 3 months after the initial surgery (local recurrence) and/or new distant lesions (metastatic recurrence). Follow-up data included time to recurrence and type of recurrence (local and/or metastatic). Patients with advanced disease underwent physical examination before each chemotherapy cycle and CT scan every 3 cycles. Time to treatment failure was defined as time between diagnosis and recurrence.

\section{Statistical analysis}

Descriptive variables (clinical, demographic, and biological) are represented with median (range) for continuous data and categorical variables with frequency (percentages) with 95\% confidence intervals (95\% CIs). Chemotherapy regimen (single versus double agent) was used to stratify time to treatment failure and overall survival analyses. Survival curves were plotted by the KaplanMeier method. We could not perform multivariate analysis because of the small sample size. Thus, we performed univariate regression analysis by the Cox proportional hazards model to explore the effect of explanatory variables such as anatomic location, age, tumor size, histological grade, gender and chemotherapy regimen on time to treatment failure and overall survival, estimating hazard ratios (HRs) and 95\% CIs.

All statistical tests were two-sided with $\mathrm{p}<0.05$ considered statistically significant. Statistical analysis involved use of SPSS v15.1 (SPSS Inc., Cary, NC, USA) and Epilnfo v3.4.2 (Centers for Disease Control and Prevention, Atlanta, GA, USA).

\section{Results}

We included data for 21 patients ( 9 females; median age 31 years [range 18-79 years]). Patient characteristics are in Table 1. Primary tumors were located on extremities $(n=8)$, abdomen or pelvis $(n=6)$, trunk $(n=4)$, and head or neck $(\mathrm{n}=3)$. The median tumor diameter was $13 \mathrm{~cm}$ [3-28 cm]. Pain, growing mass or neurological disorders was found in 20, 19 and 10 patients, respectively. 
Table 1 Patient and tumor characteristics for 21 patients with neurofibromatosis 1 and a diagnosis of malignant peripheral nerve-sheath tumors between 1993 and 2003

\begin{tabular}{|c|c|}
\hline Age, years & \\
\hline Median (range) & $31(18-79)$ \\
\hline \multicolumn{2}{|l|}{ Tumor size, cm } \\
\hline Median (range) & $13(3-28)$ \\
\hline \multicolumn{2}{|l|}{ Gender, n (\%) } \\
\hline Male & $12(57)$ \\
\hline Female & $9(43)$ \\
\hline \multicolumn{2}{|l|}{ Metastases at diagnosis, n (\%) } \\
\hline Absent & $18(86)$ \\
\hline Present & $3(14)$ \\
\hline \multicolumn{2}{|l|}{ Type of surgery, n (\%) } \\
\hline RO, complete resection & $1(5)$ \\
\hline R1, incomplete resection (microscopically) & $3(14)$ \\
\hline R2, incomplete resection (macroscopically) & $7(33)$ \\
\hline No surgery & $10(48)$ \\
\hline \multicolumn{2}{|l|}{ Histological grade (FNCLCC), n (\%) } \\
\hline 1 & $1(5)$ \\
\hline 2 & $8(38)$ \\
\hline 3 & $12(57)$ \\
\hline \multicolumn{2}{|l|}{ Pathological staging, n (\%) } \\
\hline $\mathrm{T} 1$ & $3(14)$ \\
\hline $\mathrm{T} 2$ & $18(86)$ \\
\hline \multicolumn{2}{|l|}{ Tumor site, n (\%) } \\
\hline Head and neck & $3(14)$ \\
\hline Trunk & $4(19)$ \\
\hline Extremity & $8(38)$ \\
\hline Abdomen or pelvis & $6(29)$ \\
\hline \multicolumn{2}{|l|}{ Chemotherapy, n (\%) } \\
\hline Single agent & $6(29)$ \\
\hline Combination & $15(71)$ \\
\hline \multicolumn{2}{|l|}{ Type of chemotherapy, n (\%) } \\
\hline Doxorubicin & $5(24)$ \\
\hline Ifosfamide & $1(5)$ \\
\hline Ifosfamide + anthracycline & $11(52)$ \\
\hline Ifosfamide + anthracycline + platinum salt & $4(19)$ \\
\hline
\end{tabular}

Abbreviations: FNCLCC Federation Nationale des Centres de Lutte Contre le Cancer; $T$ tumor.

FNCLCC histological grading of tumors was grade 1 $(\mathrm{n}=1,4.8 \%), 2(\mathrm{n}=8,38.1 \%)$ and $3(\mathrm{n}=12,57.1 \%)$. At the time of initial diagnosis, 16 patients presented localized disease and were candidates for curative resection. However, only 8 underwent complete macroscopic resection. For these patients, tumor margins were classified as R1 $(n=2)$ and R0 $(n=6)$. The flow for surgery is presented in
Figure 1. Three patients underwent amputation to achieve tumor-free margins.

For patients with R0 margins after resection, adjuvant treatment included chemotherapy $(\mathrm{n}=3)$, radiotherapy $(\mathrm{n}=2)$, or both $(\mathrm{n}=1)$. Four of the 6 patients with R0 margins experienced metastatic recurrence at 3, 6, 8 and 12 months, respectively. Among the 4 patients who had received chemotherapy, 2 showed metastatic recurrence at 3 and 12 months, 1 patient showed local recurrence at 31 months (in a patient who had not received radiotherapy), and 1 showed contralateral MPNST at 33 months, followed by a third MPNST during follow-up (Figure 2a). This latter patient had undergone amputation for a $26-\mathrm{cm}$ grade 3 tumor. The 2 other patients who underwent amputation died of metastatic disease.

The 2 patients with R1 margins after surgery received chemotherapy $(n=2)$, with radiotherapy $(n=1)$, but both experienced metastatic progression, at 3 and 18 months, respectively (Figure $2 \mathrm{~b}$ ).

Macroscopically incomplete resection (R2) was due to an internal location with large tumor size. The 8 patients with R2 status after surgery received post-operative palliative chemotherapy. Five also received radiotherapy that delivered a total dose of 50 Gy $(n=4)$ or $30 \mathrm{~Gy}$ $(n=1)$ before $(n=3)$ or after the end $(n=2)$ of the first-line chemotherapy. Four of the 8 patients showed rapid disease progression with chemotherapy.

Five patients did not undergo surgery and received only palliative chemotherapy. They showed progressive disease after 2, 5, 5, 7 and 9 months, respectively (Figure 2c).

All 21 patients showed treatment failure, with median time to treatment failure 7.8 months (range 2.1-128 months). At the time of the last follow-up (December 2012), 19 patients were dead, all due to cancer; 2 were still alive at 138 and 167 months, respectively, of followup. The first patient experienced 2 other MPNSTs and the second local recurrence, which was treated with surgery and radiotherapy. Both had localized grade 3 tumors with R0 resection (1 had an amputation) followed by chemotherapy early after surgery ( 6 and 32 days, respectively, as compared to a median of 101 days for the series). The chemotherapy regimen was ifosfamide and doxorubicin and was not associated with radiotherapy.

Survival at 12,18 and 24 months was $81 \%$ (95\% CI 76.4$86.6 \%), 47.6 \%(43-52.2 \%)$ and $38 \%$ (33.4-42.6\%), respectively. The median overall survival for the entire cohort was 17 months (range 2.5-167 months) (Figures 3 and 4). The median time to survival for patients with peripheral MPNSTs was 21.4 months (range 14-137 months) and for patients with axial MPNSTs, 12.6 months (range 2.5-167 months, $\mathrm{p}=0.4)$. Univariate analysis revealed no association of variables examined and time to treatment failure or overall survival. Increased tumor size at diagnosis was associated with a short time to treatment failure $(\mathrm{HR}=2.7$, 


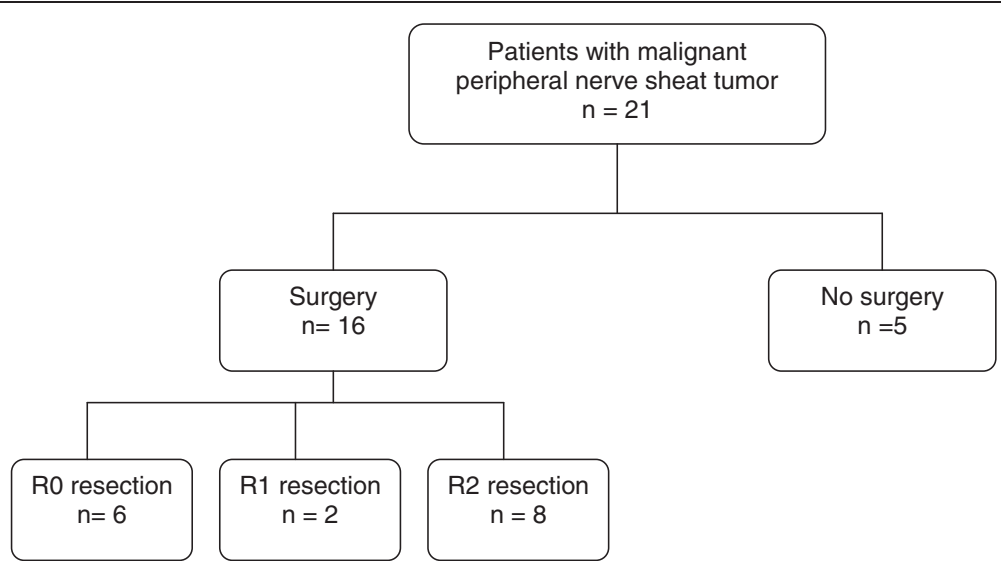

Figure 1 Flow-chart for surgery.

95\% CI 0.9-7.8, $\mathrm{p}=0.07)$ and overall survival (HR 3.1, 1.18.9). As compared with locally advanced or metastatic disease, R0 and R1 status was associated with reduced risk of death [HR 0.24, 0.05-1.17; $\mathrm{p}=0.08]$. Because of the small number of patients, we could not identify factors associated with the 2 amputation failures.

\section{Discussion}

In our experience managing NF1 with MPNSTs by chemotherapy, overall survival was poor, with a median time of 17 months and 5-year survival of $14 \%$.
Although a difference in survival between sporadic and NF1-related MPNSTs is still a matter of debate, several studies showed that the prognosis of patients with NF1 is poor $[7,10,12,14,18]$. This poor outcome can be explained by several points. For most of our patients, MPNSTs had a deep location, with large dimensions and high histological grade (poorly or undifferentiated tumors in 12 patients), as previously shown [11,12]. We reveal a low rate of complete surgery according to the localization and size of lesions at diagnosis: only 6 of the 21 patients had R0 resection, and local control rate was

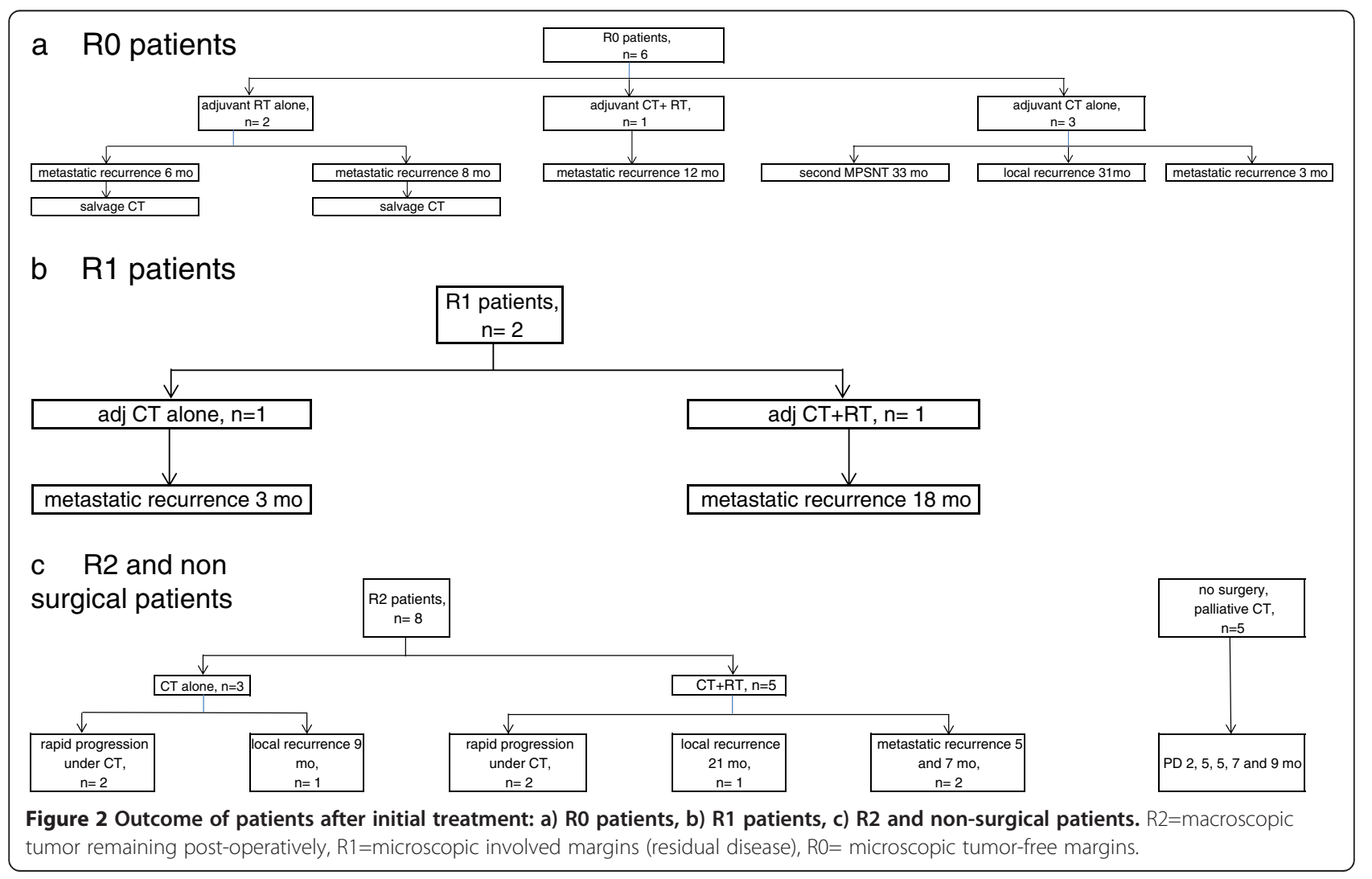




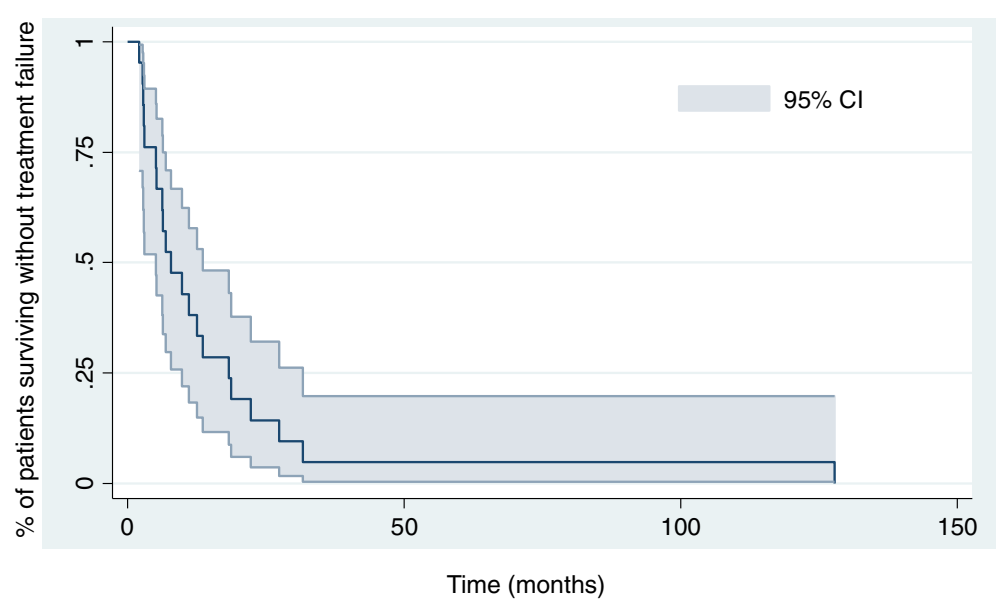

Figure 3 Kaplan-Meier curve for disease-free survival for 21 patients with malignant peripheral nerve-sheath tumors.

low. Indeed, most of the MPNSTs were internal $(\mathrm{n}=13)$ as previously shown [15]. In contrast, for patients with peripheral MPNSTs, survival was better, although not significantly, than with axial MPNSTs (median overall survival of 21.4 and 12.6 months, respectively; $\mathrm{p}=0.4$ ). This finding can be explained by internal MPNSTs (in the abdomen, pelvis, chest, etc.) usually remaining asymptomatic until they reach a large size, whereas 5-year survival is better with MPNSTs $<5 \mathrm{~cm}[8,12]$. Enlarged mass, neurological deficit and pain are clinical factors associated with malignant transformation [9]. These factors are more likely to be noted in peripheral than internal lesions.

Our series emphasizes the important role of surgery in the management of MPNST. Indeed, the 2 surviving patients underwent surgery with R0 margins, requiring amputation in 1 . We were not able to identify any prognostic factor associated with survival in these patients, but we noted that both had received doxorubicin and ifosfamide early after surgery.
Regarding amputation, our data are consistent with literature: for the 3 patients who underwent amputation, only one survived. Non-conservative surgery is associated with better local control but not with better survival in these patients, as previously reported [13]. We lack a reliable prognostic factor of success for these nonconservative surgical strategies. Further studies should be performed to identify prognostic factors, and to evaluate the role of neo-adjuvant treatments. A study of neo-adjuvant isolated limb perfusion with tumor necrosis factor showed partial response in $3 / 4$ patients with MPNST [19].

All our patients receiving chemotherapy experienced treatment failure. The place of chemotherapy in the management of NF1 with MPNSTs is still controversial [20]. In the adjuvant setting, chemotherapy is considered optional but is largely used (up to $40 \%$ of NF1 patients [18]), although doxorubin regimens have failed to show a benefit for local recurrence, distant recurrence, overall

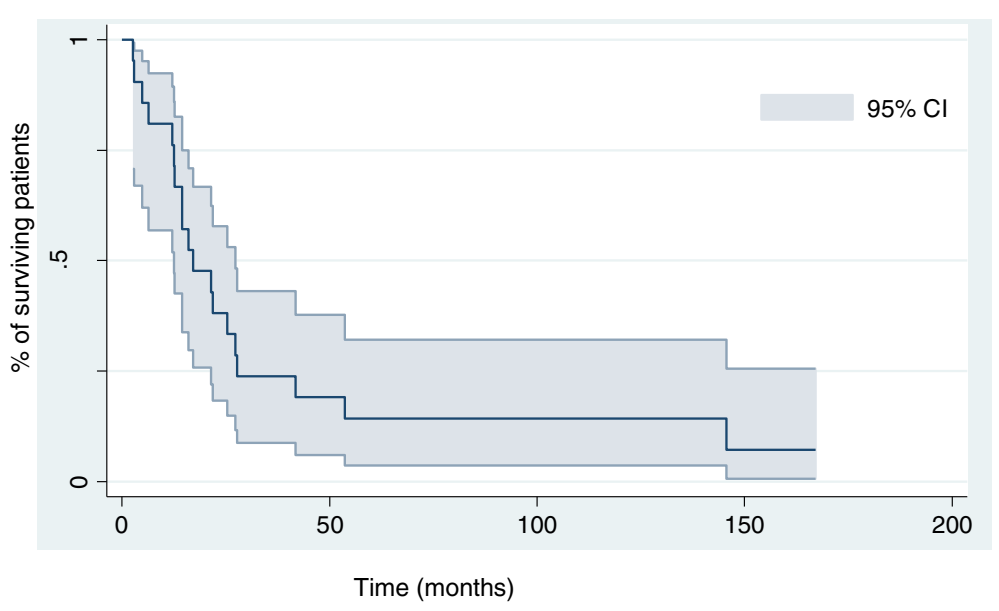

Figure 4 Kaplan-Meier curve for overall survival for 21 patients with malignant peripheral nerve-sheath tumors. 
recurrence, and overall survival [21]. Adjunct therapy with ifosfamide might improve prognosis but with more toxicity.

Metastatic MPNSTs have poor prognosis, and all our patients receiving chemotherapy without surgery for advanced or metastatic diseases experienced disease progression. Chemotherapy is considered palliative in metastatic diseases [20]. Indeed, partial response rates are about $25 \%$ to $30 \%[8,22]$.

In our retrospective experience, alternative strategies, including targeted therapy, were considered. Significant advances in the pathophysiologic features of NF1 have led to considering this new therapeutic approach. MPNSTs present complex chromosomic alterations and additional genetic mutations (p53 and cyclin-dependent kinase inhibitor $2 \mathrm{~A}$ ) that are involved in malignant transformation [23]. Loss of Nf1 gene expression induces lack of neurofibromin synthesis, a GTPase activating molecule that normally inactivates Ras and inhibits cell proliferation [24]. Aberrant activation of the Ras pathway in NF1 leads to cell proliferation. Furthermore, several signaling pathways involved in angiogenesis (cyclooxygenase 2, vascular endothelial growth factor A), cellular regulation (MKI67 etc.), epidermal growth factor (EGF receptor, pAKT, etc.) and Sonic hedgehog-Gli pathways are modified in plexiform neurofibromas associated with transformation [25].

Targeted therapies have had interesting results with NF1 tumors. Mammalian target of rapamycin inhibitors are considered a potential therapeutic approach [26-28]. More recently, preclinical studies have provided a rationale for testing mitogen-activated protein/endothelial regulated kinase inhibitors in NF1 clinical trials [29].

\section{Conclusions}

MPNSTS are currently treated as other soft-tissue sarcomas, because they are too rare to perform trials with a sufficient number of patients. Overall survival with MPNSTS is poor, and the usual chemotherapy used for soft-tissue sarcomas does not improve the outcome. Recent advances in the molecular biology of MPNSTS may provide new targeted therapies.

\section{Abbreviations \\ Cl: Confidence interval; FNCLCC: Federation Nationale des Centres de Lutte Contre le Cancer; HR: Hazard ratio; MPNSTs: Malignant peripheral nerve- sheath tumors; NF1: Neurofibromatosis 1.}

\section{Competing interests}

The author's declare no competing interests.

No financial support was provided for this work from pharmaceutical industry or other institutions.

\section{Authors' contributions}

$\mathrm{OZ}$ made substantial contributions to the analysis and interpretation of data and was involved in drafting the manuscript. EF made substantial contributions to the acquisition, analysis and interpretation of data and was involved in drafting the manuscript. LZ made substantial contributions to the analysis and interpretation of data and was involved in revising the manuscript critically for important intellectual content. ES performed the statistical analysis, made substantial contributions to the analysis and interpretation of data and was involved in revising the manuscript critically for important intellectual content. NO performed histopathological analysis of the tumor specimens and was involved in revising the manuscript critically for important intellectual content. EB made substantial contributions to the acquisition of data and was involved in revising the manuscript critically for important intellectual content. PW made substantial contributions to the analysis and interpretation of data and was involved in revising the manuscript critically for important intellectual content. LVA made substantial contributions to the interpretation of data and was involved in drafting the manuscript. All authors have read and approved the final version to be published.

\section{Acknowledgments}

This study was presented at the "Journées Dermatologiques De Paris" in 2006 as a poster.

\section{Author details}

${ }^{1}$ Department of Dermatology, Referral center for Neurofibromatosis, Henri Mondor Hospital, UPEC, Créteil, France. ${ }^{2}$ Department of Medical Oncology, Georges Pompidou European Hospital, Paris, France. ${ }^{3}$ Department of Medical Oncology, Avicenne Hospital, Bobigny, France. ${ }^{4}$ Department of Pathology, Henri Mondor Hospital, UPEC, Créteil, France. ${ }^{5}$ Department of Medical Oncology, Cancer Institute "Ion Chiricuta", Cluj-Napoca, Romania.

${ }^{6}$ Department of Dermatology, Henri-Mondor Hospital, 51 Av du Maréchal de Lattre de Tassigny, F-94010 Créteil Cedex, France.

Received: 15 May 2013 Accepted: 4 August 2013

Published: 23 August 2013

\section{References}

1. Gutmann DH, Aylsworth A, Carey JC, Korf B, Marks J, Pyeritz RE, Rubenstein A, Viskochil D: The diagnostic evaluation and multidisciplinary management of neurofibromatosis 1 and neurofibromatosis 2. Jama 1997, 278(1):51-57.

2. Zehou O, Bularca S, Bastuji-Garin S, Ortonne N, Valeyrie-Allanore L, Wolkenstein P, Duong TA: Neurofibromatosis 1 phenotype associated to malignant peripheral nerve sheath tumours: a case-control study. J Eur Acad Dermatol Venereol 2013, 27(8):1044-1047.

3. Walker $L$, Thompson D, Easton D, Ponder B, Ponder M, Frayling I, Baralle D: A prospective study of neurofibromatosis type 1 cancer incidence in the UK. Br J Cancer 2006, 95(2):233-238.

4. Duong TA, Sbidian E, Valeyrie-Allanore L, Vialette C, Ferkal S, Hadj-Rabia S, Glorion C, Lyonnet S, Zerah M, Kemlin I, et al: Mortality associated with neurofibromatosis 1: a cohort study of 1895 patients in 1980-2006 in France. Orphanet J Rare Dis 2011, 6:18.

5. McGaughran JM, Harris DI, Donnai D, Teare D, MacLeod R, Westerbeek R, Kingston H, Super M, Harris R, Evans DG: A clinical study of type 1 neurofibromatosis in north west England. J Med Genet 1999, 36(3):197-203.

6. Holtkamp N, Reuss DE, Atallah I, Kuban RJ, Hartmann C, Mautner VF, Frahm S, Friedrich RE, Algermissen B, Pham VA, et al: Subclassification of nerve sheath tumors by gene expression profiling. Brain Pathol 2004, 14(3):258-264.

7. Evans DG, Baser ME, McGaughran J, Sharif S, Howard E, Moran A: Malignant peripheral nerve sheath tumours in neurofibromatosis 1. J Med Genet 2002, 39(5):311-314.

8. Ferner RE, Gutmann DH: International consensus statement on malignant peripheral nerve sheath tumors in neurofibromatosis. Cancer Res 2002, 62(5):1573-1577

9. Valeyrie-Allanore L, Ismaili N, Bastuji-Garin S, Zeller J, Wechsler J, Revuz J, Wolkenstein P: Symptoms associated with malignancy of peripheral nerve sheath tumours: a retrospective study of 69 patients with neurofibromatosis 1. Br J Dermatol 2005, 153(1):79-82.

10. Ducatman BS, Scheithauer BW, Piepgras DG, Reiman HM, Ilstrup DM: Malignant peripheral nerve sheath tumors. A clinicopathologic study of 120 cases. Cancer 1986, 57(10):2006-2021.

11. Kourea HP, Bilsky MH, Leung DH, Lewis JJ, Woodruff JM: Subdiaphragmatic and intrathoracic paraspinal malignant peripheral nerve sheath tumors: 
a clinicopathologic study of 25 patients and 26 tumors. Cancer 1998, 82(11):2191-2203.

12. Porter DE, Prasad V, Foster L, Dall GF, Birch R, Grimer RJ: Survival in malignant peripheral nerve sheath tumours: a comparison between sporadic and neurofibromatosis type 1-Associated tumours. Sarcoma 2009, 2009:756395

13. Hruban RH, Shiu MH, Senie RT, Woodruff JM: Malignant peripheral nerve sheath tumors of the buttock and lower extremity. A study of 43 cases. Cancer 1990, 66(6):1253-1265.

14. Wong WW, Hirose T, Scheithauer BW, Schild SE, Gunderson LL: Malignant peripheral nerve sheath tumor: analysis of treatment outcome. Int J Radiat Oncol Biol Phys 1998, 42(2):351-360.

15. Sordillo PP, Helson L, Hajdu SI, Magill GB, Kosloff C, Golbey RB, Beattie EJ: Malignant schwannoma-clinical characteristics, survival, and response to therapy. Cancer 1981, 47(10):2503-2509.

16. Casali PG, Jost L, Sleijfer S, Verweij J, Blay JY: Soft tissue sarcomas: ESMO clinical recommendations for diagnosis, treatment and follow-up. Ann Oncol 2009, 20(Suppl 4):132-136.

17. Guillou L, Coindre JM, Bonichon F, Nguyen BB, Terrier P, Collin F, Vilain MO, Mandard AM, Le Doussal V, Leroux A, et al: Comparative study of the National Cancer Institute and French Federation of Cancer Centers Sarcoma Group grading systems in a population of 410 adult patients with soft tissue sarcoma. J Clin Oncol 1997, 15(1):350-362.

18. Kolberg M, Holand M, Agesen TH, Brekke HR, Liestol K, Hall KS, Mertens F, Picci P, Smeland S, Lothe RA: Survival meta-analyses for $>1800$ malignant peripheral nerve sheath tumor patients with and without neurofibromatosis type 1. Neuro Oncol 2013, 15(2):135-147.

19. Lejeune FJ, Pujol N, Lienard D, Mosimann F, Raffoul W, Genton A, Guillou L, Landry M, Chassot PG, Chiolero R, et al: Limb salvage by neoadjuvant isolated perfusion with TNFalpha and melphalan for non-resectable soft tissue sarcoma of the extremities. Eur J Surg Oncol 2000, 26(7):669-678.

20. Clark MA, Fisher C, Judson I, Thomas JM: Soft-tissue sarcomas in adults. N Engl J Med 2005, 353(7):701-711.

21. Pervaiz N, Colterjohn N, Farrokhyar F, Tozer R, Figueredo A, Ghert M: A systematic meta-analysis of randomized controlled trials of adjuvant chemotherapy for localized resectable soft-tissue sarcoma. Cancer 2008, 113(3):573-581.

22. Van Glabbeke M, van Oosterom AT, Oosterhuis JW, Mouridsen H, Crowther D, Somers R, Verweij J, Santoro A, Buesa J, Tursz T: Prognostic factors for the outcome of chemotherapy in advanced soft tissue sarcoma: an analysis of 2,185 patients treated with anthracycline-containing first-line regimens-a European Organization for Research and Treatment of Cancer Soft Tissue and Bone Sarcoma Group Study. J Clin Oncol 1999, 17(1):150-157.

23. Pasmant $E$, Vidaud $M$, Vidaud $D$, Wolkenstein $P$ : Neurofibromatosis type 1 : from genotype to phenotype. J Med Genet 2012, 49(8):483-489.

24. Lee MJ, Stephenson DA: Recent developments in neurofibromatosis type 1. Curr Opin Neurol 2007, 20(2):135-141.

25. Pasmant E, Masliah-Planchon J, Levy P, Laurendeau I, Ortonne N, Parfait B, Valeyrie-Allanore L, Leroy $\mathrm{K}$, Wolkenstein $\mathrm{P}$, Vidaud $\mathrm{M}$, et al: Identification of genes potentially involved in the increased risk of malignancy in NF1microdeleted patients. Mol Med 2011, 17(1-2):79-87.

26. Zou CY, Smith KD, Zhu QS, Liu J, McCutcheon IE, Slopis JM, Meric-Bernstam F, Peng Z, Bornmann WG, Mills GB, et al: Dual targeting of AKT and mammalian target of rapamycin: a potential therapeutic approach for malignant peripheral nerve sheath tumor. Mol Cancer Ther 2009, 8(5):1157-1168

27. Endo M, Yamamoto H, Setsu N, Kohashi K, Takahashi Y, Ishii T, lida K Matsumoto Y, Hakozaki M, Aoki M, et al: Prognostic Significance of AKT/ mTOR and MAPK Pathways and Antitumor Effect of mTOR Inhibitor in NF1-Related and Sporadic Malignant Peripheral Nerve Sheath Tumors. Clin Cancer Res 2013, 19(2):450-461.

28. Agulnik M: New developments in mammalian target of rapamycin inhibitors for the treatment of sarcoma. Cancer 2012, 118(6):1486-1497.

29. Jessen WJ, Miller SJ, Jousma E, Wu J, Rizvi TA, Brundage ME, Eaves D, Widemann B, Kim MO, Dombi E, et al: MEK inhibition exhibits efficacy in human and mouse neurofibromatosis tumors. J Clin Invest 2013, 123(1):340-347.

doi:10.1186/1750-1172-8-127

Cite this article as: Zehou et al.: Chemotherapy for the treatment of malignant peripheral nerve sheath tumors in neurofibromatosis 1: a 10year institutional review. Orphanet Journal of Rare Diseases 2013 8:127.

\section{Submit your next manuscript to BioMed Central and take full advantage of:}

- Convenient online submission

- Thorough peer review

- No space constraints or color figure charges

- Immediate publication on acceptance

- Inclusion in PubMed, CAS, Scopus and Google Scholar

- Research which is freely available for redistribution 